\title{
Volatile organic compounds, respirable dust, and personal factors related to prevalence and incidence of sick building syndrome in primary schools
}

\author{
D Norbäck, $M$ Torgén, C Edling
}

\begin{abstract}
Possible relations between incidence and prevalence of sick building syndrome (SBS), indoor exposures, and personal factors were studied in a four year longitudinal study among personnel $(n=129)$ in six primary schools. The mean concentration of carbon dioxide was above the recommended value of $0.08 \mu 1 / 1(800 \mathrm{ppm})$ in all schools, indicating a poor outdoor air supply. Indoor concentration of volatile hydrocarbon (VOC) was enhanced at high room temperatures. Respirable dust, but not concentration of VOC was enhanced at lower ventilation rates and high air humidity. Chronic SBS was related to VOC, previous wall to wall carpeting in the schools, hyperreactivity, and psychosocial factors. Incidence of new SBS was related to concentration of respirable dust, current smoking, and the psychosocial climate. Remission of hyperreactivity, decrease in sick leave owing to airway illness, removal of carpeting in the schools, and moving from new to old dwellings resulted in a decrease in SBS score. It is concluded that SBS is of multifactorial origin, related to a variety of factors and exposures. The total concentration of hydrocarbons is a simple and convenient measure of exposure, which also seems to be a predictor of chronic symptoms. Further investigations on the effect of temperature, ventilation, and air humidity on SBS should consider how these factors may influence the chemical composition of the air. Because poor air quality in schools could also affect the children, it may have implications for the state of health of a large proportion of the population.
\end{abstract}

The sick building syndrome (SBS) has various nonspecific symptoms such as eye, skin, and upper

Department of Occupational Medicine, University Hospital, S-751 85 Uppsala, Sweden

D Norbäck, $M$ Torgén, C Edling airway irritation, headache, and fatigue. ${ }^{1}$ Such symptoms are not uncommon in the general population but several studies have shown that these symptoms are more common among people working in so called sick buildings. ${ }^{2-12}$ Most of these studies only dealt with symptoms among office workers. ${ }^{2-79}$ A survey performed in a tricounty region in Sweden, however, showed that not only offices but also schools and day care centres were common among the sick buildings known by the occupational health care centres. ${ }^{10}$

In two recent studies, we found a relation between the prevalence of symptoms in sick buildings and the concentration of volatile organic hydrocarbons (VOC) ${ }^{11}$ and the presence of wall to wall carpets. ${ }^{12}$ Other studies have shown that the amount of fleecy material in the building, ${ }^{4}$ age of buildings, ${ }^{5}$ room temperature, ${ }^{9}$ the type of ventilation system, ${ }^{23}$ and passive smoking ${ }^{9}$ influence the prevalence of symptoms. Personal factors may also have an influence. ${ }^{411}$ Although several cross sectional studies on the sick building syndrome have been published, ${ }^{2-68}$ longitudinal studies aimed to identify factors related to changes of symptoms are sparse. ${ }^{712}$

One aim of this study was to identify indoor exposures and personal factors related to the prevalence of chronic SBS symptoms and the incidence of new symptoms. Another was to study the effect of changes over time in personal and building related factors on the prevalence of SBS.

\section{Material and methods}

Data were obtained from an earlier longitudinal study based on a questionnaire and performed in May 1982 and May 1986 to study the effect on different types of symptoms of the removal of wall to wall carpets in schools. ${ }^{12}$ This information was related to chemical measurements of the indoor air quality performed during November 1986, after the questionnaire study was finished.

The study base consisted of personnel in six out of a total of 14 primary schools in a major Swedish city (Uppsala). They were observed during the period 1982-6. To produce a sufficient number of subjects exposed to wall to wall carpets in schools, the study included all personnel from the two schools with wall 
to wall carpets. Also, all personnel in a random sample of two newer and two older primary schools with hard floor coatings in the city of Uppsala were included. The two older schools were stone buildings without forced ventilation. The two newer schools and the two schools with wall to wall carpets were one floor brick buildings equipped with forced ventilation without air conditioning. All six schools were built before the so called energy crisis in 1974 .

In 1982 a self administered questionnaire was sent to all personnel $(n=205)$ in the six selected schools. During the period 1982-6, the wall to wall carpets were gradually removed from the schools and replaced with hard PVC floor coating. Other than the removal of the carpets, no other change in building material, ventilation system, or activity occurred during the investigation period. In 1986, the same questionnaire was mailed to those in the initial study group still at work in the primary schools of Uppsala $(\mathrm{n}=141)$.

\section{ASSESSMENT OF SYMPTOMS AND PERSONAL FACTORS}

The occurrence of symptoms among the school personnel was recorded by a self administered questionnaire. The questionnaire required information on personal factors such as smoking habits, atopy, hyperreactivity, sick leave, work stress, work satisfaction, and climate of cooperation at work. It contained questions requiring "yes" or "no" answers on 16 different symptoms and covered the previous six months. No information on the severity or duration of the symptoms was gathered. The changes in and persistence of each symptom were noted by comparing the answers in 1982 and 1986 . For each person, a symptom change score, ranging from -16 to +16 was assigned by comparing the number of yes answers on symptoms in 1982 with those in 1986. A particular symptom reported both in 1982 and 1986 was considered as a chronic symptom, and the prevalence of chronic symptoms was calculated. A particular symptom reported in 1986 but not in 1982 was considered as a new symptom, and the four year incidence of new symptoms was calculated. A particular symptom reported in 1982 but not in 1986 was considered as a disappeared symptom, and the four year incidence of disappearance of symptoms was also calculated.

Work stress, work satisfaction, and climate of cooperation were measured on an analogue rating scale. ${ }^{13} \mathrm{~A}$ psychosocial dissatisfaction index ranging from 0 to $100 \%$ was calculated by adding the perceived degree of work dissatisfaction, work stress, and lack of work cooperation and dividing by a factor of three. In order that the results of the 1982 questionnaire did not influence the longitudinal study, these results were not reported to the participants. The 16 questions on symptoms and the analogue rating scales are given in the appendix.

\section{ASSESSMENT OF EXPOSURE}

Data on age of building, type of ventilation, air conditioning, or air humidification were gathered by interviewing the maintenance men of the schools. Information on environmental tobacco smoke, the presence of fleecy material on the walls, and the presence of wall to wall carpets on the floors in the different classrooms were obtained both from the participants and by inspection made by us. Information on present or earlier damage from moisture in the buildings was gathered from the safety engineer of the occupational health care centre serving all schools in the city. One of the schools (the newest) had enhanced water content in the concrete floor, caused by capillary transportation of water from the ground into the floor. In this school growth of fungi and bacteria in the floor was verified during 1989 by the occupational health care unit. In the other schools no water damage or problems related to moisture were known.

Age of each participant's dwelling and information on wall to wall carpets in the home environment were also obtained from the questionnaires. During 1982, methods for investigating the chemical exposure were not available in our department. During 1986, however, it was possible to perform both outdoor and indoor measurements. Outdoors, air temperature and concentrations of respirable dust and VOC were measured. Indoors, room temperature, relative humidity, and concentrations of respirable dust, carbon dioxide, formaldehyde, and VOC were determined.

Air temperature and humidity were recorded with an Assman psychrometer. Indoor concentrations of formaldehyde were measured with glass fibre filters impregnated with 2,4-dinitro-phenylhydrazine, ${ }^{14}$ the air sampling rate being $0.25 \mathrm{l} / \mathrm{min}$ during two hours. The filters were analysed by liquid chromatography. Indoor carbon dioxide concentration was measured by colorimetric detector tubes (Draeger $0.01 \% / a$ ), calibrated to Fourier transform infrared spectroscopic analysis. ${ }^{15}$ Concentrations of respirable dust were measured by a direct reading instrument based on light scattering (Sibata $\mathrm{P}-5 \mathrm{H} 2$ ) calibrated by the manufacturer to $0.3 \mu \mathrm{m}$ particles of stearic acid.

Volatile organic compounds in the indoor and outdoor air were sampled on charcoal sorbent tubes (SKC 226-01), the air sampling rate being $1 \mathrm{l} / \mathrm{min}$ during two hours. The charcoal tubes were then kept at $-20^{\circ} \mathrm{C}$, until desorbed with $1 \mathrm{ml}$ of carbon disulphide before analysis, which was performed within a week from the sampling day by a gas chromatograph (Hewlett Packard model 5880) equipped with flame ionisation detector and packed glass columns. The injector temperature was $150^{\circ} \mathrm{C}$, the detector temperature $200^{\circ} \mathrm{C}$, and the carrier gas flow $30 \mathrm{ml} / \mathrm{min}$ of nitrogen. Fifteen common hydrocarbons were identified and quantified by 
using an external standard technique comparing the retention times of the samples and the standards on two different columns. When quantifying low boiling uncalibrated hydrocarbons (C3-C12), the response factor of $\mathrm{n}$-decane was used; high boiling unknown hydrocarbons ( $>\mathrm{C12}$ ), utilised the response factor of a mixture of high boiling hydrocarbons (dodecyl benzenes). The total concentration of identified and unidentified hydrocarbons in air (total VOC expressed as $\mu \mathrm{g} / \mathrm{m}^{3}$ ) was calculated.

Four indoor charcoal samples, two formaldehyde samples, and one outdoor charcoal sample (each with a sampling period of two hours) were taken in each school. All measurements were performed between 12.30 and $2.30 \mathrm{pm}$. In one of the schools, one of two separate buildings was painted inside during the summer and autumn of 1986 after the questionnaire study was completed. In this school, only VOC measurements from the non-painted building were used when calculating the mean concentrations of VOC. Also, 5-10 short term (thrẹe minutes) measurements of air temperature and humidity, and concentrations of respirable dust and carbon dioxide were taken at the end of lessons. Finally, the arith- metic average exposure were calculated for each school.

\section{STATISTICAL METHODS}

Average exposure among subjects with or without a particular symptom was compared by Student's $t$ test. The multifactorial analysis of the symptom change score was by multiple linear regression with the symptom score as independent variable. The influence of different factors on the prevalence of chronic symptoms or the incidence of new symptoms was analysed by both linear and logistic regression using the EPILOG statistical package. Logistic and linear regression analyses were performed in five stages. Firstly, all potential confounders were forced into the model. Secondly, all significant confounders were maintained in the model. Thirdly, the exposure variables were forced into the model one by one. Fourthly, all significant exposure variables were included, and finally, all non-significant exposure variables were excluded. In all statistical analysis, two tailed tests and a five per cent level of significance were used.

Table 1 Selected demographic and exposure data for school personnel $(n=129)$ working in primary schools of $U p p s a l a$ during 1982-6

\begin{tabular}{|c|c|c|c|}
\hline Characteristic & $\begin{array}{l}\text { Prevalence in } \\
1982(\%)\end{array}$ & $\begin{array}{l}\text { Prevalence in } \\
1986(\%)\end{array}$ & $\begin{array}{l}\text { Prevalence } 1982 \\
\text { or } 1986(\%)\end{array}$ \\
\hline $\begin{array}{l}\text { Proportion of women } \\
\text { Current tobacco smoker } \\
\text { Subjects with signs of atopy } \dagger \\
\text { Non-specific hyperreactivity } \ddagger \\
\text { Environmental tobacco smoke at work } \S \\
\text { Wall to wall carpet in the workplace } \\
\text { Fleecy wall material in the workplace } \\
\text { Wall to wall carpet in the dwelling } \\
\text { Living in a dwelling built after } 1975\end{array}$ & $\begin{array}{l}81 \\
16 \\
18 \\
31 \\
11 \\
32 \\
16 \\
36 \\
23\end{array}$ & $\begin{array}{r}81 \\
13 \\
18 \\
32 \\
7 \\
9 \\
18 \\
31 \\
20\end{array}$ & $\begin{array}{l}81 \\
16 \\
21 \\
41 \\
11 \\
37 \\
25 \\
40 \\
29\end{array}$ \\
\hline
\end{tabular}

$\star$ Subjects with the characteristic in 1982 , in 1986 , or both years.

tSubjects with a history of asthma, hay fever, or eczema in childhood.

†Easily irritated eyes or respiratory tract during exposure to non-specific irritants (tobacco smoke, exhaust gases, organic solvents).

$\$$ Annoyance at environmental tobacco smoke at work.

Table 2 Four year incidence and prevalence of symptoms among primary school personnel without wall to wall carpets in their work rooms during period 1982-6 $(n=81)$

\begin{tabular}{|c|c|c|c|}
\hline Type of symptom & $\begin{array}{l}\text { Incidence of } \\
\text { new symptoms }(\% / 4 y)\end{array}$ & $\begin{array}{l}\text { Incidence of } \\
\text { disappearance } \\
\text { of symptoms }(\% / 4 y)\end{array}$ & $\begin{array}{l}\text { Prevalence } \\
\text { of permanent } \\
\text { symptoms }(\%)\end{array}$ \\
\hline $\begin{array}{l}\text { Eye irritation } \\
\text { Swollen eyelids } \\
\text { Nasal catarrh } \\
\text { Blocked up nose } \\
\text { Dryness in the throat } \\
\text { Sore throat } \\
\text { Irritative cough } \\
\text { Headache } \\
\text { Abnormal tiredness } \\
\text { Sensation of getting a cold } \\
\text { Nausea } \\
\text { Facial itching } \\
\text { Facial rash } \\
\text { Itching on the hands } \\
\text { Rashes on the hands } \\
\text { Eczema }\end{array}$ & $\begin{array}{r}6 \\
5 \\
3 \\
5 \\
8 \\
3 \\
8 \\
9 \\
15 \\
10 \\
5 \\
3 \\
2 \\
2 \\
2 \\
11\end{array}$ & $\begin{array}{r}6 \\
1 \\
6 \\
8 \\
10 \\
5 \\
8 \\
9 \\
8 \\
13 \\
4 \\
3 \\
1 \\
5 \\
4 \\
5\end{array}$ & $\begin{array}{r}7 \\
4 \\
4 \\
6 \\
9 \\
1 \\
0 \\
9 \\
22 \\
8 \\
0 \\
3 \\
2 \\
5 \\
4 \\
9\end{array}$ \\
\hline
\end{tabular}


Table 3 Variation of indoor air concentration $\left(\mu \mathrm{g} / \mathrm{m}^{3}\right)$ of respirable dust and chemical compounds between primary schools $(n=6)$

\begin{tabular}{|c|c|c|c|}
\hline Compounds & Arithmetic mean & Geometric mean (SD) & Range \\
\hline $\begin{array}{l}\text { Respirable dust } \\
\text { Aromatics } \\
\text { n-Alkanes } \dagger \\
\text { Terpenest } \\
\text { Butanols } \S \\
\text { 2-Ethylhexanol } \\
\text { Unidentified low boiling hydrocarbons } \pi \\
\text { Unidentified high boiling hydrocarbons } \| \\
\text { Total indoor concentration of volatile hydrocarbons }\end{array}$ & $\begin{array}{r}16 \\
39 \\
5 \\
17 \\
8 \\
2 \\
36 \\
23 \\
130\end{array}$ & $\begin{array}{r}15(1 \cdot 4) \\
36(1 \cdot 6) \\
4(3 \cdot 0) \\
13(2 \cdot 3) \\
6(1 \cdot 8) \\
1(3 \cdot 3) \\
32(1 \cdot 8) \\
16(2 \cdot 8) \\
120(1 \cdot 4)\end{array}$ & $\begin{array}{c}8-24 \\
19-71 \\
<1-8 \\
4-35 \\
4-20 \\
<1-6 \\
16-74 \\
4-54 \\
70-180\end{array}$ \\
\hline
\end{tabular}

$\star$ Sum of toluene, m-xylene, o-xylene, p-xylene, and ethylbenzene.

+ Sum of n-octane, n-nonane, $n$-decane, and $n$-undecane.

$\ddagger$ Sum of $\alpha$-pinene, $\delta$-carene, and limonene.

$\S$ Sum of $n$-butanol and iso-butanol.

TSum of unidentified hydrocarbon with a retention time below $\mathrm{n}$-dodecane.

$\|$ Sum of unidentified hydrocarbons with a retention time equal to or greater than $\mathrm{n}$-dodecane.

\section{Results}

In 1982, 192 of $205(94 \%)$ subjects answered the first questionnaire. Four years later, 141 persons still worked in the primary schools of Uppsala. The repeated questionnaire was answered by 129 of these $141(91 \%)$. Of these 129 participants in the longitudinal study, 97 persons still worked in the initial six schools, and 32 persons had moved to other schools in Uppsala where no exposure measurements were available. Table 1 presents the demographic, psychosocial, and exposure data for all participants in the longitudinal study. Mean age of the group was 46 in 1986. Mean reported days of sick leave due to respiratory illness were three days per six months during 1982 and four days per six months during 1986 , and the mean value of the psychosocial dissatisfaction index was $37 \%$ in 1982 and $41 \%$ in 1986.

During the investigation period, 81 of the 129 participants had no carpeting in their workroom. These participants were used to calculate prevalence of chronic symptoms, incidence of new symptoms, and incidence of disappearance of symptoms among personnel without exposure to carpeting in their workroom (table 2).

In all schools, the concentration of formaldehyde was below the detection limit $\left(<10 \mu \mathrm{g} / \mathrm{m}^{3}\right)$. The mean indoor concentration of VOC ranged from 70 to $180 \mu \mathrm{g} / \mathrm{m}^{3}$ (table 3 ). The greatest variation was

Table 4 Means and ranges of climatological and ventilation data on primary schools $(n=6)$

\begin{tabular}{lc}
\hline & $\begin{array}{l}\text { Arithmetic mean } \\
\text { (range) }\end{array}$ \\
\hline Room temperature $\left({ }^{\circ} \mathrm{C}\right)$ & $22(19-24)$ \\
Relative air humidity $(\%)$ & $38(26-44)$ \\
Carbon dioxide concentration $(\mu \mathrm{l} / \mathrm{l})$ & $1290(950-1950)$ \\
Outdoor air rate ${ }^{\star}(\mathrm{l} / \mathrm{s} /$ person) & $5(3-8)$ \\
\hline
\end{tabular}

*Calculated from the measured carbon dioxide concentration assuming carbon dioxide emission of $18 \mathrm{l} / \mathrm{h}$ a person, equilibrium, and an outdoor carbon dioxide concentration of $330 \mu \mathrm{l} / \mathrm{l}$. found for $\mathrm{n}$-alkanes and high boiling hydrocarbons. The largest group of compounds consisted of aromatics and unidentified low boiling compounds. During the measurements, the outdoor temperature varied from 1 to $8^{\circ} \mathrm{C}$ (mean $4^{\circ} \mathrm{C}$ ), the outdoor respirable concentration of dust was $2-7 \mu \mathrm{g} / \mathrm{m}^{3}$, and concentration of total hydrocarbon was $11-55 \mu \mathrm{g} / \mathrm{m}^{3}$.

Table 4 records indoor climatological conditions and ventilation data. The mean indoor concentration of carbon dioxide was above the recommended value ${ }^{16}$ of $800 \mu \mathrm{l} / 1(800 \mathrm{ppm})$ in all schools, indicating poor outdoor air supply. Concentration of respirable dust was enhanced at lower ventilation rates (fig 1) and at higher relative air humidity (fig 2 ), but no significant relation between these factors and the concentration of total VOC could be shown. A positive relation was found, however, between room

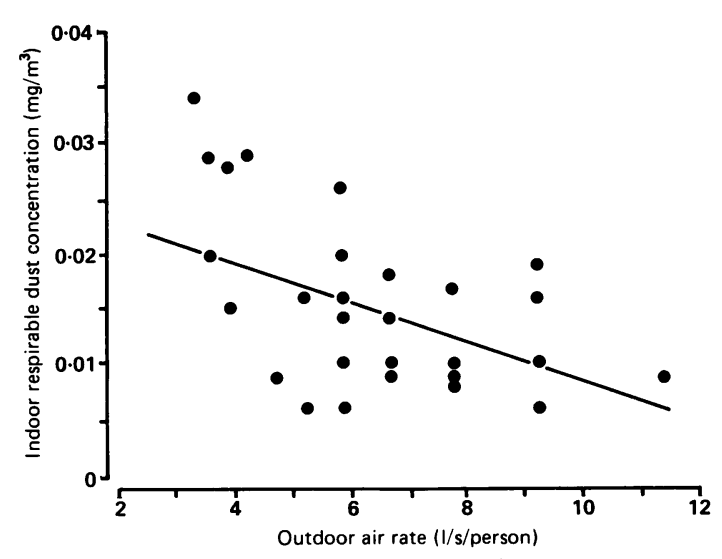

Figure 1 Linear regression values of the indoor respirable dust concentration as a function of the outdoor air rate. (DUST $=-0.0018$ VENT $+0.026 ; R=0.50, n=34$, $p<0.01$; where DUST is the respirable dust concentration $\left(\mathrm{mg} / \mathrm{m}^{3}\right), V E N T$ is the outdoor air rate (l/s/person), $R$ is the correlation coefficient, $n$ is the number of measurements, and $p$ is the two tailed $p$ value of the slope). 


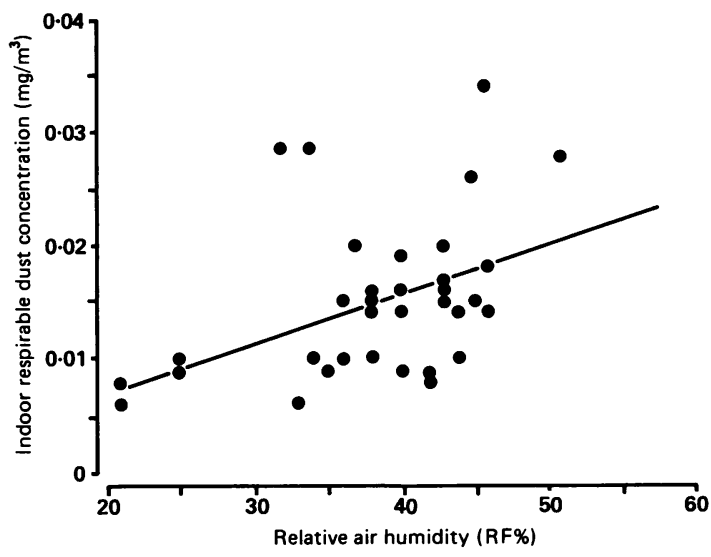

Figure 2 Linear regression values of the indoor respirable dust concentration as a function of the relative air humidity. (DUST $=0.00043$ HUMIDITY $-0.002 ; R=0.44$, $n=35, p<0.01 ;$ where DUST is the respirable dust concentration $\left(\mathrm{mg} / \mathrm{m}^{3}\right)$, HUMIDITY is the relative air humidity $(R F \%), R$ is the correlation coefficient, $n$ is the number of measurements, and $p$ is the two tailed $p$ value of the slope).

temperature and concentration of VOC (fig 3).

The initial analysis of data showed that persons with at least one chronic symptom on average were exposed to higher room temperature, lower air humidity, and higher concentrations of both total VOC and particular types of compounds (table 5). Both logistic and linear regression analysis showed

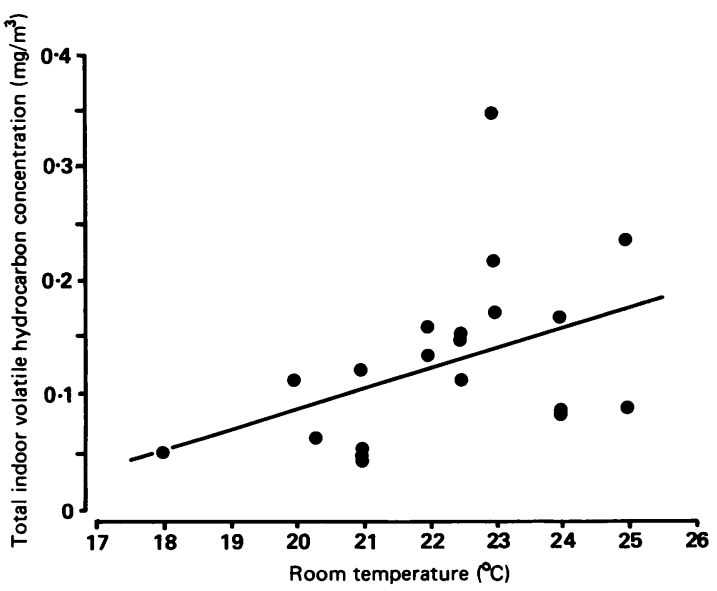

Figure 3 Linear regression values of total indoor volatile hydrocarbon concentration as a function of room temperature. (VOC $=0.018$ TEMP $-0.26 ; R=0.42$; $n=21 ; p<0.05 ;$ where VOC is the total indoor volatile hydrocarbon concentration $\left(\mathrm{mg} / \mathrm{m}^{3}\right), T E M P$ is the room temperature $\left({ }^{\circ} \mathrm{C}\right), R$ is the correlation coefficient, $n$ is the number of measurements and $p$ is the two tailed $p$ value of the slope).
Table 5 Relation between prevalence of at least one chronic symptom among primary school employees $(n=97)$ and different indoor exposure variables

\begin{tabular}{lll}
\hline Type of variable & $\begin{array}{l}\text { Exposure } \\
\text { ratio }\end{array}$ & $\begin{array}{l}\text { Two tailed } \\
\text { pvalue }\end{array}$ \\
\hline Room temperature & 1.04 & $<0.01$ \\
Relative air humidity & 0.93 & $<0.05$ \\
Carbon dioxide & 1.02 & NS \\
Respirable dust & 0.97 & NS \\
Aromatics & 1.33 & $<0.01$ \\
n-Alkanes & 1.44 & $<0.01$ \\
Terpenes & 1.47 & $<0.01$ \\
Butanols & 1.41 & $<0.05$ \\
2-Ethylhexanol & 0.99 & NS \\
Unidentified low boiling hydrocarbons & 0.92 & NS \\
Unidentified high boiling hydrocarbons & 1.24 & NS \\
Total indoor concentration of volatile & 1.21 & $<0.01$ \\
$\quad$ hydrocarbons & & \\
\hline
\end{tabular}

^For definition of groups of compounds see table 3.

tRatio of exposure (arithmetic mean) among subjects with at least one chronic symptom $(\mathrm{N}=48)$ and subjects without any chronic symptom $(\mathrm{N}=49)$.

† Significance of difference in arithmetic mean exposure calculated from Student's $t$ test.

that two personal factors were related to prevalence of at least one chronic symptom-namely, nonspecific hyperreactivity $(p<0.05)$ and psychosocial dissatisfaction index $(p<0.01)$. Wall to wall carpets in the work environment $(p<0.01)$ but not in the home were also related to chronic symptoms. In the final regression model (table 6) concentration of VOC, but not room temperature or air humidity correlated significantly with the prevalence of chronic symptoms $(p<0.01)$. Both the concentration of total hydrocarbon and four identified groups

Table 6 Regression analysis of prevalence of at least one chronic symptom among school personnel $(\boldsymbol{n}=97)$ as function of two significant confounders and two significant exposure variables $(p<0.05)$

\begin{tabular}{lcc}
\hline Variable & $\begin{array}{c}\text { Logistic model } \\
\text { Coefficient }(S E)\end{array}$ & $\begin{array}{c}\text { Linear model } \\
\text { Coefficient }(S E)\end{array}$ \\
\hline $\begin{array}{l}\text { Hyperreactivity } \dagger \\
\text { Psychosocial dissatisfaction } \\
\text { index (PSD) } \ddagger\end{array}$ & $1 \cdot 09^{\star}(0 \cdot 55)$ & $0 \cdot 18^{\star}(0 \cdot 09)$ \\
$\begin{array}{l}\text { Wall to wall carpet in the } \\
\text { workplace }\end{array}$ & $7 \cdot 03^{\star \star}(2 \cdot 25)$ & $1 \cdot 22^{\star \star}(0 \cdot 33)$ \\
Total VOCT & $1 \cdot 64^{\star \star}(0 \cdot 58)$ & $0 \cdot 30^{\star \star}(0 \cdot 10)$ \\
Constant & $17 \cdot 8^{\star}(7 \cdot 91)$ & $2 \cdot 88^{\star}(1 \cdot 26)$ \\
& $-5 \cdot 73$ & $-0 \cdot 48$
\end{tabular}

*Two tailed $\mathrm{p}<0.05 ; \star \star$ two tailed $\mathrm{p}<0.01$.

† Subjects reporting hyperreactivity in 1982, in 1986 , or both years, $0=$ absence, $1=$ presence.

† Continuous variable ranging from 0 to $1 ; 0=$ absence; $1=$ presence.

$\pi$ Continuous variable expressed as $\mathrm{mg} / \mathrm{m}^{3}$.

Sixteen variables were non-significant (p > 0.05) predictors of presence of chronic symptoms-namely, age, sex, atopy, current tobacco smoking, environmental tobacco smoke, days of sick leave due to respiratory illness, indoor room temperature, indoor air humidity, indoor carbon dioxide concentration, indoor respirable dust concentration, age of schools, mechanical ventilation in schools, fleecy wall material in schools, moisture damage in schools, age of dwelling, and wall to wall carpets in the dwelling. 
Table 7 Relation between prevalence of different types of chronic symptoms and total indoor volatile hydrocarbon concentration

\begin{tabular}{llll}
\hline Type of symptom & $\begin{array}{l}\text { Prevalence } \\
(\%)\end{array}$ & $\begin{array}{l}\text { VOC } \\
\text { ratio }\end{array}$ & $\begin{array}{l}\text { Two tailed } \\
\text { pvalue }\end{array}$ \\
\hline Airway $\ddagger$ & 20 & $1 \cdot 19$ & $<0.01$ \\
General§ & 40 & 1.28 & $<0.01$ \\
Eyel & 13 & 1.24 & $<0.05$ \\
Dermal:| & 14 & 1.05 & NS
\end{tabular}

* Ratio of arithmetic mean concentration among subjects with the particular type of chronic symptom $(n=48)$ and subjects without any chronic symptom $(n=49)$.

†Calculated from Student's $t$ test.

$\ddagger$ Nasal catarrh, blocked up nose, dry or sore throat, irritative cough.

§Headache, abnormal tiredness, sensation of getting a cold, nausea.

TEye irritation, swollen eyelids.

iEczema, facial itching, facial rash, itching or rashes on the hands.

of compounds were significantly related to the prevalence of chronic symptoms, namely terpenes, aromatics $(\mathrm{C} 7-\mathrm{C} 8)$, n-alkanes $(\mathrm{C} 8-\mathrm{C} 11)$ and butanols $(\mathrm{p}<0.05)$. These compounds were partly intercorrelated to each other and to the concentration of total hydrocarbon $\left(R^{2}=29\right.$ to $\left.84 \%\right)$. The highest concentrations of VOC were measured in the oldest building with poorest ventilation, and in the newest building with moisture damage to the floor. Respirable dust, concentration of carbon dioxide, age of building, or mechanical ventilation system did not correlate significantly with chronic symptoms. In a further analysis, the relation between different types of chronic symptoms and the concentration of total hydrocarbons was investigated. Concentration of total hydrocarbon was related to chronic airway $(\mathrm{p}<0.01)$, chronic general $(\mathrm{p}<0.01)$, and chronic eye symptoms $(p<0.05)$ but not to chronic skin symptoms (table 7).

Subjects reporting at least one new symptom on average were exposed to lower room temperature and higher air humidity (table 8). Logistic analysis and

Table 8 Relation between incidence of at least one new symptom and different indoor exposure variables among primary school employees $(\boldsymbol{n}=97)$

\begin{tabular}{lll}
\hline Type of variable & $\begin{array}{l}\text { Exposure } \\
\text { ratio } \dagger\end{array}$ & $\begin{array}{l}\text { Two tailed } \\
\text { p-value }\end{array}$ \\
\hline Room temperature & 0.98 & $<0.05$ \\
Relative air humidity & 1.07 & $<0.05$ \\
Carbon dioxide & 1.07 & NS \\
$\begin{array}{l}\text { Respirable dust } \\
\text { Total indoor concentration of volatile } \\
\text { hydrocarbons }\end{array}$ & 0.11 & NS \\
\hline
\end{tabular}

*For definition of groups of compounds see table 4.

† Ratio of exposure (arithmetic mean) among subjects with at least one new symptom $(n=43)$ and subjects without any new symptom $(n=54)$.

$\ddagger$ Significance of difference in arithmetic mean exposure calculated from Student's $t$ test.
Table 9 Regression analysis of incidence of at least one new symptom among school personnel $(n=97)$ as a function of two significant confounders and one significant exposure variable $(p<0.05)$

\begin{tabular}{|c|c|c|}
\hline Variable & $\begin{array}{l}\text { Logistic model } \\
\text { Coefficient ( } S E \text { ) }\end{array}$ & $\begin{array}{l}\text { Linear model } \\
\text { Coefficient ( } S E \text { ) }\end{array}$ \\
\hline $\begin{array}{l}\text { Current smoking } \dagger \\
\text { Psychosocial dissatisfaction }\end{array}$ & $0.94^{\star \star}(0.35)$ & $0 \cdot 14^{\star \star \star}(0.05)$ \\
\hline $\begin{array}{l}\text { (PSD) index } \ddagger \\
\text { Indoor respirable dust }\end{array}$ & $11 \cdot 70^{\star \star \star}(2 \cdot 84)$ & $1 \cdot 73^{\star \star \star}(0.33)$ \\
\hline $\begin{array}{l}\text { concentration } \S \\
\text { Constant }\end{array}$ & $\begin{aligned} & 0.20^{\star \star}(0.08) \\
- & 7 \cdot 53\end{aligned}$ & $\begin{aligned} & 0.027^{\star} \star(0.01) \\
- & 0.60\end{aligned}$ \\
\hline
\end{tabular}

${ }^{\star}$ Two tailed $\mathrm{p}<0.05 ;{ }^{\star \star}$ two tailed $\mathrm{p}<0.01 ;{ }^{\star \star \star}$ two tailed $\mathrm{p}<0.001$.

to $=$ Non-smoker, $1=1-7 \mathrm{cig} / \mathrm{d} ; 2=8-15 \mathrm{cig} / \mathrm{d} ; 3=>15 \mathrm{cig} /$ d.

+Continuous variable ranging from 0 to 1 .

$\S$ Continuous variable expressed as $\mu \mathrm{g} / \mathrm{m}^{3}$.

Seventeen studied variables were non-significant $(p>0.05)$ predictors of incidence of new symptoms-namely, age, sex, atopy, hyperreactivity, days of sick leave due to respiratory illness, environmental tobacco smoke, indoor air temperature, indoor air humidity, indoor volatile hydrocarbon concentration, indoor carbon dioxide concentration, age of schools, mechanical ventilation in schools, wall to wall carpet in the workplace, fleecy wall material in schools, moisture damage in schools, age of dwelling, and wall to wall carpets in the dwelling.

linear regression analysis both showed that two personal factors were related to the incidence of at least one new symptom-namely, current smoking $(p<0.01)$ and psychosocial dissatisfaction index $(\mathrm{p}<0.001)$. In the final regression model (table 9) concentration of respirable dust, but not room temperature or air humidity correlated significantly with the incidence of new symptoms $(p<0.01)$. The highest concentrations of dust were measured in the oldest building with poorest ventilation, and in the newest building with moisture damage in the floor. Concentrations of carbon dioxide and VOC, age of building, or mechanical ventilation system did not correlate significantly with the incidence of new

Table 10 Relation between incidence of different types of new symptoms and indoor respirable dust concentration

\begin{tabular}{llll}
\hline Type of symptom & $\begin{array}{l}\text { Incidence } \\
(\% / 4 y)\end{array}$ & $\begin{array}{l}\text { Dust } \\
\text { ratio }\end{array}$ & $\begin{array}{l}\text { Two tailed } \\
\text { pvalue }\end{array}$ \\
\hline Airway ${ }_{+}^{\star}$ & 11 & $1 \cdot 11$ & NS \\
Generali & 22 & $1 \cdot 10$ & NS \\
Eyeil & 9 & $1 \cdot 31$ & $<0 \cdot 01$ \\
Dermal $\star$ & 18 & 1.07 & NS \\
\hline
\end{tabular}

* Ratio of arithmetic mean concentration among subjects with particular type of new symptom $(n=43)$ and individuals without any new symptom $(n=54)$.

†Significance of difference in arithmetic mean exposure calculated from Student's $t$ test.

†Nasal catarrh, blocked up nose, dry or sore throat, irritative cough.

THeadache, abnormal tiredness, sensation of getting a cold, nausea.

|Eye irritation, swollen eyelids.

$\star \star$ Eczema, facial itching, facial rash, itching or rashes on the hands. 
Table 11 Multiple linear regression analysis of changes in individual symptom score $(-16$ to +16$)$ among school personnel $(n=124 \dagger)$ as a function of changes in four significant predictor variables $(p<0.05)$

\begin{tabular}{ll}
\hline Variable & $\begin{array}{l}\text { Partial regression } \\
\text { coefficient }(S D)\end{array}$ \\
\hline Hyperreactivity $\ddagger$ & $1 \cdot 28^{\star}(0 \cdot 50)$ \\
Sick leave§ & $0 \cdot 14^{\star}(0 \cdot 07)$ \\
Wall to wall carpet in the workplace $\pi$ & $0 \cdot 78^{\star}(0.39)$ \\
Building age of the dwelling & $1 \cdot 18^{\star}(0.54)$ \\
\hline
\end{tabular}

«Two tailed p $<0.05 ;{ }^{\star}$ two tailed p $<0.01$.

tIncomplete answers from five subjects.

†Difference in number of symptoms between subjects reporting development of hyperreactivity compared with those with permanent non-hyperreactivity.

$\$$ Number of symptoms per annual week of sick leave due to airway illness.

IDifference in number of symptoms between subjects in workplaces where wall to wall carpets were removed compared with subjects without such carpets in their workplaces during 1982-6.

IDifference in number of symptoms between subjects moving from old to new buildings compared with those continuously living in old houses.

Three variables were non-significant $(p>0.05)$ predictors of symptom score changes-namely, psychosocial dissatisfaction index, fleecy material on the walls, and wall to wall carpets in the dwelling.

symptoms. Concentration of dust was significantly related to the incidence of eye symptoms $(p<0.05)$ but not to the incidence of other symptoms (table 10).

Multiple regression analysis of the influence of changes on the SBS showed that changes in two personal factors were positively related to a change in number of symptoms (table 11). These factors were non-specific hyperreactivity $(p<0.01)$ and sick leave due to airway illness $(p<0.05)$. Removal of wall to wall carpets in the workplace reduced the number of symptoms $(p<0.05)$. Moving from old to new dwellings increased the SBS score, and moving from new to old dwellings decreased the number of SBS symptoms ( $p<0.05)$.

\section{Discussion}

We have shown that a relation exists between SBS symptoms and measured environmental factors such as VOC and respirable dust. Also, environmental indicators such as the age of the dwelling and carpeting in schools and personal factors such as current smoking, hyperreactivity, and psychosocial dissatisfaction were related to the symptoms.

Selection bias can occur as a result of both a low response rate and incorrect study design. The schools included in this study were selected on the basis of two criteria, namely age of building and the presence of wall to wall carpets in the schools, regardless of the prevalence of symptoms. Also, the participation rate was high in our study, and therefore the probability of selection bias due to loss of subjects from the studied sick building groups was minimised. The study was restricted, however, to subjects remaining in the schools of Uppsala during the period of investigation. In theory, poor quality of indoor air or other work related factors could cause sensitive subjects to leave the school environment, and thus the study would underestimate the true effect of the environment. In the first part of this study, however, the opposite was shown, namely an increased number of symptoms in 1982 among those who remained in the schools during 1982-6 compared with those who left the environment of the school during this period. ${ }^{12}$

Another problem regarding validity is the possible response bias due to awareness of the exposure. Some building related factors such as type of ventilation or type of floor material are known by the inhabitants of the buildings. Thus it is impossible to perform a "blind" field study of the effects of these factors. On the other hand, the concentration of indoor air pollutants was not known by the study subjects as the exposure measurements were performed after the questionnaire study was completed. The results of the measurements could therefore not influence the responses to the questionnaire. Also, only specific exposures and specific factors were found to correlate with the number of symptoms.

Finally, in multivariate modelling of epidemiological data, the type of regression model or mass significance may influence the result. ${ }^{17}$ In this study, both linear and logistic regression analysis resulted in the same parameters showing significance. With regard to the discussed aspects of internal validity, we do not think that the result of our study is due to response bias, selection bias, mass significance, or the selection of a particular regression model.

Some of the symptoms included in the sick building syndrome are similar to symptoms of common colds. In our study, changes in the frequency of sick leave owing to respiratory illness corresponded to changes of symptoms but the average rate of sick leave was not related to prevalence of chronic symptoms or incidence of new symptoms. Sick leave in airway illness has earlier been shown to be one factor related to the prevalence of symptoms in sick buildings in a cross sectional study. ${ }^{11}$

Signs of hyperreactivity were related to changes of symptoms and chronic symptoms. Besides atopy, hyperreactivity may be related to smoking. ${ }^{18}$ Also, common infections of the airway may induce temporary bronchial hyperreactivity among normal subjects. ${ }^{19}$ In sick buildings, self reported hyperreactivity had earlier been shown to be related to the prevalence of symptoms. ${ }^{11}$

The mean degree of psychosocial dissatisfaction was strongly related to both prevalence of chronic symptoms and particularly to the incidence of new symptoms. This is in agreement with earlier cross sectional studies where psychosocial factors were found to be related to this type of symptom. ${ }^{51120-22}$ 
Although chemical stimulation of the trigeminus or olfactorius nerves has been suggested as an explanation of the sick building syndrome,${ }^{23}$ there are few epidemiological studies published that test this hypothesis. Concentrations of formaldehyde one order of magnitude higher than the detection limit of this study have been shown to correlate with symptoms related to the sick building syndrome. ${ }^{24} 25$ In an earlier study, the total indoor concentration of VOC in sick buildings was significantly related to the number of symptoms. ${ }^{11}$ In the so called town hall study, the highest prevalence of symptoms was found in the building with the highest concentration of total hydrocarbons. ${ }^{5}$ Apart from these two cross sectional studies, we have not found any epidemiological studies on the effect of volatile hydrocarbons other than formaldehyde on the sick building syndrome. In a Danish exposure chamber study, the effect of two hours of exposure to a mixture of 20 common indoor hydrocarbons was evaluated. ${ }^{26} \mathrm{~A}$ total hydrocarbon concentration of $5 \mathrm{mg} / \mathrm{m}^{3}$ induced irritation in the eyes, nose, and throat. The effects were acute and showed no signs of adaptation. Also, a finger span performance test showed decreased scores during exposure. ${ }^{26} \mathrm{We}$ are not aware of other experimental data on humans on irritative effects of hydrocarbon mixtures at exposure concentrations lower than $5 \mathrm{mg} / \mathrm{m}^{3}$.

In the present study, all schools had an average concentration of carbon dioxide above the recommended value of $800 \mu \mathrm{l} / 1(800 \mathrm{ppm})^{16}$ but no significant association between carbon dioxide concentrations and symptoms could be shown. Concentration of carbon dioxide is a good measure of the fresh air supply for a person but it is a reliable indicator of air quality only if humans or human activities are the dominating source of indoor air pollution. As shown by Fanger, ${ }^{27}$ non-human factors such as the buildings or the ventilation systems could be dominating sources of air pollution. This may explain why no association between symptoms and concentration of carbon dioxide was found.

In a Finnish report, room temperatures above $22^{\circ} \mathrm{C}$ were related to an excess of SBS symptoms. ${ }^{9}$ Both room temperature and air humidity were significantly related to such symptoms in our initial statistical analysis. We also showed covariation between these climatological factors and the indoor concentrations of VOCs and respirable dust. In our final regression models, however, chemical factors but not room temperature or air humidity were significantly related to symptoms.

The Danish town hall study found an association between a large amount of fleecy material in offices and a higher prevalence of the sick building syndrome, ${ }^{4}$ but did not differentiate between fleecy material on the floor and on the walls. We were able to separate the effect of fleecy material in different parts of the environment, and we found that only wall to wall carpets in the work environment were related to the sick building syndrome. This could be explained by the fact that these carpets were old and more contaminated than carpets in the dwellings or fleecy material on the walls of the schools. From the result of an observational study on dust and microorganisms in carpets, it appears that wall to wall carpets in schools are more contaminated than wall to wall carpets in offices. ${ }^{26}$

In our study, we found a relation between concentration of respirable dust and incidence of eye symptoms. To our knowledge, no other study on the sick building syndrome has shown a relation between airborne dust and such symptoms. As no further chemical or biological analysis of the dust was performed, it is difficult to speculate on the mechanisms of the induction of symptoms. Our finding, however, indicates that aerosols, as well as VOCs, should be considered when investigating the sick building syndrome.

There are few studies on the relation between the home environment and the sick building syndrome. We found a positive association between change of symptoms and moving from old dwellings to dwellings built after the energy crisis (1974). This agrees with the town hall study, where the highest prevalence of symptoms was found in new office buildings. ${ }^{5}$ A negative association between age of building and indoor hydrocarbon concentration in pre-schools had been reported earlier. ${ }^{29}$

The sick building syndrome is of multifactorial origin, related to both personal factors and environmental factors. Because certain personal factors are related to the prevalence and incidence of the syndrome, these factors must be carefully controlled in epidemiological studies. Investigations on the effect of conventional parameters of indoor climate such as temperature, humidity, or ventilation on the sick building syndrome should consider how these factors may influence the indoor concentration of both volatile chemicals and aerosols.

Although some types of hydrocarbons might contribute to the sick building syndrome more than other compounds, the sum of hydrocarbon concentrations is a simple and convenient measure that seems to be a predictor of chronic symptoms. The findings of this study may be explained by sensory irritation from the complex mixture of hydrocarbons occurring in the indoor air. Irritation mediated by the trigeminal nerve shows little or no adaption over time. ${ }^{30}$ Effects of air pollution other than sensory irritation may also contribute to chronic airway symptoms, as suggested by the finding that asthma and allergic rhinitis increased among Swedish conscripts. ${ }^{31}$ In the future, investigations on the sick building syndrome should consider both the possibility of acute and chronic effects of the modern non- 
industrial indoor environment. As most youths in the industrialised world spend a decade or more in schools, impairment of health due to poor quality of indoor air in schools may have implications for the health state of a large proportion of the population.

1 Akimenko VV, Andersen I, Lebowitz MD, Lindvall T. The "sick" building syndrome. In: Indoor air. Vol 6. Stockholm: Swedish Council for Building Research, 1986:87-97.

2 Finnegan MJ, Pickering CAC, Burge PS. The sick building syndrome: prevalence studies. $\mathrm{Br}$ Med J 1984;289:1573-5.

3 Burge S, Hedge A, Wilson S, Bass JH, Robertson A. Sick building syndrome: a study of 4373 office workers. Ann Occup Hyg 1987;31:493-504.

4 Valbjørn O, Skov P. Danish Indoor Climate Study Group. Influence of indoor climate on the sick building syndrome prevalence. In: Indoor air ' 87 . Vol 2 Proceedings of the fourth international conference on indoor air quality and climate. Berlin (West): Institute for Water, Soil, and Air Hygiene, 1987: 593-7.

5 Skov P, Valbjørn O. Danish Indoor Climate Study Group. The "sick" building syndrome in the office environment: The Danish town hall study. Environment International 1987;13:339-49.

6 Turiel I, Hollowell CD, Miksch RR, Rudy JV, Young RA, Coye $M J$. The effects of reduced ventilation on indoor air quality in an office building. Atmospheric Environment 1983;17:51-63.

7 Sterling E, Sterling $T$. The impact of different ventilation levels and fluorescence lighting types on building illness: an experimental study. Can J Public Health 1983;74:385-92.

8 Norbäck D, Rand G, Michel I, Amcoff S. The prevalence of symptoms associated with sick buildings and polluted industrial environments as compared to unexposed reference groups without expressed dissatisfaction. Environment International 1989;15:85-94.

9 Jaakkola JJK, Heinonen OP, Seppänen O. Sick building syndrome, sensation of dryness and thermal comfort in relation to room temperature in an office building: need for individual control of temperature. Environment International 1989; 15:163-8.

10 Widström J, Norbäck D. An inventory of sick buildings among workplaces connected to occupational health centers in the counties of Gävleborg, Kopparberg and Uppsala. In: Proceedings of the 37th Nordic meeting of work environment, Gothenburg, Stockholm: National Institute of Occupational Health, 1988:292-3. (In Swedish.)

11 Norbäck D, Michel I, Widström J. Indoor air quality and personal factors related to the sick building syndrome. Scand J Work Environ Health 1990;16:121-8.

12 Norbäck $D$, Torgen $M$. A longitudinal study relating carpeting with sick building syndrome. Environment International 1989; 15:129-35.

13 Bond $\mathbf{A}$, Lader $M$. The use of analogue rating scales in rating subjective feelings. Br J Med Psychol 1974;47:211-8.

14 Andersson K, Hallgren C, Levin J-O, Nilsson C-A. Chemosorption sampling and analysis of formaldehyde in air: influence on recovery during the simultaneous sampling of formaldehyde, phenol, furfural and furfuryl alcohol. Scand J Work Environ Health 1981;7:282-9.

15 Johanson G, Norbäck D, Ancker K. Field evaluation of direct reading tubes for the measurement of carbon dioxide in indoor air. In: Proceedings of the 38th Nordic meeting of work environment. Sandefjord 1989. Oslo: National Institute of Work Environment, 1989:153-4. (In Swedish.)

16 Berglund B, Berglund U, Lindvall T. Characterisation of indoor air quality and "sick buildings". ASHRAE Tran 1984;90: 1045-55.

17 Greenland S. Modeling and variable selection in epidemiologic analysis. Am J Publ Health 1989;79:340-9.

18 Pride NB. Bronchial hyperreactivity in smokers. Eur Respir $J$ 1988;1:485-7.

19 Empey DW, Laitinen LA, Jacobs L, Gold WM, Nadel JA. Mechanisms of bronchial hyperreactivity in normal subjects after upper respiratory tract infection. Am Rev Respir Dis 1976;113:131-9.

20 Skov P, Valbjørn O, Danish Indoor Climate Study Group. Influence of personal characteristics, job-related factors and psychosocial factors on the sick building syndrome. Scand $J$ Work Environ Health 1989;15:286-95.

21 Michel I, Norbäck D, Edling C. An epidemiologic study of the relation between symptoms of fatigue, dental amalgam and other factors. Swed Dent J 1989;13:33-8.

22 Morrison L, Hawkins L. The role of stress in the sick building syndrome. In: Indoor air ' 87 . Vol 2. Proceedings of the fourth international conference on indoor air quality and climate. Berlin (West): Institute for Water, Soil, and Air Hygiene, 1987: 566-71.

23 Berglund B, Lindvall T. Sensory reactions to "sick buildings". Environment international 1986;12:147-59.

24 Main DM, Hogan TJ. Health effects of low-level exposure to formaldehyde. J Occup Med 1983;25:896-900.

25 Olsen JH, Dössing M. Formaldehyde induced symptoms in day care centers. Am Ind Hyg Assoc J 1982;43:366-70.

26 Molhave L, Bach B, Pederson OF. Human reactions to low concentrations of volatile organic compounds. Environment International 1986;12:167-75.

27 Fanger PO. A solution to the sick building mystery. In: Indoor air '87. Vol 4. Proceedings of the fourth international conference on indoor air quality and climate. Berlin (West): Institute for Water, Soil and Air Hygiene, 1987:49-55.

28 Gravesten S, Larsen L, Gyntelberg F, Skov P. Demonstration of microorganisms and dust in schools and offices. Allergy 1986;41:520-5.

29 Berglund B, Johansson I, Lindvall T. A longitudinal study of air contaminants in a newly built preschool. Environmental International 1982;8:111-5.

30 Engen T. Perception of odor and irritation. Environmental International 1986;12:177-87.

31 Åberg N. Asthma and allergic rhinitis in Swedish conscripts. Clinical and Experimental Allergy 1989;19:59-63.

Accepted 14 May 1990

\section{Appendix}

\section{SELF ADMINISTERED QUESTIONNAIRE}

Symptom items

Have you during the last six months:

Had rashes on the hands or forearms?

Had rashes on the face or throat?

Had eczema?

Had itching hands or forearms?

Had itching face or throat?

Had eye irritation (redness of the eyes)?

Had swollen eyelids?

Often had headache?

Often felt nausea?

Often had nasal catarrh?

Often had a stopped up nose?

Often felt dryness in the throat?

Often felt as if you would get a cold?

Often had sore throat?

Often had irritative cough?

Often felt tired and out of sorts?

These symptoms were scored $0=$ no, $1=$ yes.

(2) Psychosocial rating scales (0 to 100\%)

Mark on the scales below:

How satisfied are you with your working conditions?

Totally satisfied

Perfectly satisfied

How stressful is your work?

No stress

Extremely stressful

How is the climate of cooperation at your workplace?

Very poor

Very good 